\title{
Survey Based Study to Assess the Principles, Assumptions, and Processes in Establishing Biologics Assets as a Fast to FIH (First-In-Human)
}

\author{
Article by Olga Karagiozova \\ Clinical Research, Texila American University, USA \\ E-mail: olgakaragiozova@gmail.com
}

\begin{abstract}
Biologics development represents a substantial advancement in the pharmaceutical industry because of their promise and huge success in the oncology, immunoscience, and cardiovascular disease areas. Prior to entering the marketed product development phase, each biopharmaceutical needs to go through series of stages that will allow or disallow the biologics asset to become a commercialized product. Each of those phases includes development planning and designing of studies to test relevant hypotheses to support the drug label if approved.

In this study, the findings from the survey that was conducted previously as planned. It is organized into various sections, which include a summary of the study approach, the original research questions and hypotheses, the actual number of interviewed participants and response rate, and the general quantitative results of the survey in terms of gender, age, department, and experience. The chapter then presents qualitative results from content analysis and then finally, an in-depth discussion of the implication of these findings.
\end{abstract}

Keywords: Fast to First in Human, Biologics, study approach, survey.

\section{Introduction}

This study will review the findings from the survey that was conducted previously as planned to assess the Principles, assumptions, and processes established to designate biologics assets as a Fast to FIH (First-in-Human) program and the associated core concepts for the utilization of low and highrisk activities, timelines and functional level expectations. The research is organized into different sections, which include also the summary of the study approach, the original research questions and hypotheses, the response rate and general quantitative results of the survey.

The main aim of the proposed study is to find out the principles, assumptions, and processes utilized in designating biologics assets as a Fast to FIH (First-in-Human) program, as well as, streamline the processes of high and low-risk activities using Fast to First-In-Human (FIH) model and their successful implementation and subsequent readiness for regulatory submission of the clinical trial application (CTA).

First, the researcher will concentrate on seeking to establish whether there is sufficient evidence indicating that there have been newer, assumptions, and processes established to designate biologics assets as a Fast to FIH (First-in-Human) program. Along with that, the researcher will concentrate on the aspect of if significant changes occur of the associated core concepts for the utilization of low and high-risk activities, timelines, and functional level expectations in the designation of biologics assets as a Fast to FIH (null hypothesis).

Second objective is associated with the alternate hypothesis which will concentrate on the fact that there are no newer principles, assumptions, and processes established to designate biologics assets as a Fast to FIH (First-in-Human) program as well as there is no significant change in the associated core concepts for the utilization of low and high-risk activities.

\section{Research methodology}

This article will discuss the research design that the researcher will use in this study. It also presents the target population and sampling frame, sample and sampling techniques, data collection instruments, pilot study, and data processing and analysis methods that the researcher will employ in this particular study. 


\section{Research design}

The proposed research will utilize a qualitative survey study approach. Therefore, a survey will be carried out on 5 leading pharmaceutical companies, Amgen Inc. Eli Lilly and Company, AstraZeneca, Johnson \& Johnson, and Merck \& Company Inc., using mailed questionnaires. Questionnaires will be used to collect information pertaining to the principles, assumptions, and processes utilized in designating biologics assets as a Fast to FIH (First-in-Human) program, as well as, streamline the processes of high and low-risk activities using Fast to First-In-Human (FIH) model and their successful implementation and subsequent readiness for regulatory submission of the clinical trial application (CTA). The questionnaires will be directed to the members of the research and development departments of the 5 pharmaceutical companies. A qualitative approach has been chosen as an ideal methodology because the information required to answer the main research question and test the hypotheses cannot be quantified (Rahman, 2016; Tolley, Ulin, \& Robinson, 2013). Therefore, qualitative information regarding the phenomenon under study will be collected.

\section{Target population}

The target population of this study will be leading pharmaceutical companies, especially global companies. The researcher targets were leading pharmaceutical companies because unlike the other smaller pharmaceutical companies, and they engage in the manufacture of FIH drugs. Therefore, they are most likely to expected to utilize various principles, assumptions, and processes in designating biologics assets as a Fast to FIH (First-in-Human) program, as well as, streamline the processes of high and low-risk activities using Fast to First-In-Human (FIH) models. Moreover, they are always keen to enhance the successful implementation process to facilitate subsequent readiness for regulatory submission of the clinical trial application (CTA). Therefore, the study targets the leading pharmaceutical companies from the United States. It is not only the companies that the study will target, but also its key employees and management teams, which are most likely to have the information that is required.

\section{Sampling frame}

In the case of this research, the researcher will make various important considerations when choosing the appropriate sampling frame. Particularly, a consideration of the relationship between the research target population and the unit of selection will be made by the researcher. Given that the target population determines the unit of selection, the proposed study will consider organizations that manufacture Fast to FIH (First-in-Human) drugs, utilizing high and low-risk processes to enhance the successful implementation and subsequent readiness for regulatory submission of the clinical trial application (CTA). In addition, the unit of selection determines the probability of selection at the last stage. Therefore, the researcher will be guided by these principles while choosing the sampling frame and the sample for study from the target population.

The researcher will ensure that the sampling frame captures, in a statistical sense, the target population by choosing the most representative sample from the target population. The researcher will also ensure that the information to be obtained from the investigation will be as perfect as possible by choosing a complete, accurate, and up-to-date sampling frame. As much as this ideal property may be unattainable in the proposed survey, the researcher will ensure that it meets these requirements by constructing the sampling frame from scratch rather than using an existing one. Consequently, the sample frame will be up-to-date and as accurate as possible, though it may be as complete as may be required.

The researcher will ensure that the sampling frame meets the basic conditions of high-quality by assessing it in terms of how well the frame's idealized properties are related to the targeted population. Particularly, the researcher will ensure that the rules of selection are duly followed such that every member of the target population will have an equal chance of inclusion just like the rest. The chance of selection, in this case, will be known and non-zero. Therefore, the researcher will ensure that these conditions are met so that the sampling frame's quality may be objectively assessed.

The proposed study will use a sampling frame of organizations that manufacture FIH drugs, particularly leading pharmaceutical companies as a tool that will enable the researcher to objectively 
select a sample of units from the population of all units. In this case, it will be considered whether the sample results will lead to generalizable conclusions and whether the proposed sampling plan will be possible within time and budget limitations. In addition, the researcher will consider whether the sampling procedure will be practically feasible. Finally, the researcher will investigate whether the proposed sampling scheme will provide results that will address survey objectives with appropriate measures of precision. It should be noted that the quality of the sampling frame usually affects the quality of the sample. The researcher will ensure that there is adequate information on the frame available so that sampling, data collection, weighting, and non-response bias analyses can be conducted. Therefore, the researcher will ensure that the sampling frame of this proposed study up to date and includes only one record for each member of the target population.

\section{Sampling techniques}

Both probability and non-probability sampling will be utilized in the proposed study. The reason for this is that all the leading will have an equal chance of being selected to form the total of 5 in which surveys will be carried while not all the organizational members of the 5 companies will have a chance of being selected as informants. Instead, the researcher will purposively select informants from among the researchers of the 5 companies' research and development departments, quality and control units, and senior management personnel teams.

A sample of 5 pharmaceutical companies has been chosen because it will represent the entire population significantly. Moreover, the study focuses on the leading pharmaceutical companies. Given that the sampling frame consists of 17 companies, then settling on 5 such companies in the sample is appropriate and is expected to provide valid and reliable findings that are significant enough. Random sampling enhances the control of research processes. The approach also facilitates the avoidance of the influence that can be caused by the researchers such that they are not able to select elements of the sample that suit their needs. In this case, the researcher will use a random number table to select the 5 pharmaceutical companies which will be included in the survey.

\section{Sample size}

As indicated, the sample will consist of 5 pharmaceutical companies, which have been randomly selected from a sampling frame of 17 companies. The researcher will purposively interview 15 employees from each of the 5 selected companies. Therefore, a total of 75 employees will be interviewed during the survey. The researcher will interview 3 employees from each company's senior management team, 6 employees from the quality control unit of each of the 5 companies, and 6 employees from the research and development department of each of the five companies. Therefore, a total of 15 senior management personnel, 30 quality, and control unit employees, and 30 research and development employees will be interviewed.

Table 1. Intended interview schedule

\begin{tabular}{|l|l|l|l|l|}
\hline \multirow{2}{*}{ Company Name } & \multicolumn{2}{|l|}{ Department } & \\
\cline { 2 - 5 } & $\begin{array}{l}\text { Senior } \\
\text { Management }\end{array}$ & $\begin{array}{l}\text { Quality and Control } \\
\text { Unit }\end{array}$ & $\begin{array}{l}\text { Research } \\
\text { and } \\
\text { Developmen } \\
\text { t }\end{array}$ & \\
\hline Amgen Inc & 3 & 6 & 6 & $\mathbf{1 5}$ \\
\hline Eli Lilly \& Company & 3 & 6 & 6 & $\mathbf{1 5}$ \\
\hline AstraZeneca & 3 & 6 & 6 & $\mathbf{1 5}$ \\
\hline Johnson\&Johnson & 3 & 6 & 6 & $\mathbf{1 5}$ \\
\hline $\begin{array}{l}\text { Merck \& Company } \\
\text { Inc. }\end{array}$ & 3 & 6 & 6 & $\mathbf{1 5}$ \\
\hline TOTAL & $\mathbf{1 5}$ & $\mathbf{3 0}$ & $\mathbf{3 0}$ & $\mathbf{7 5}$ \\
\hline
\end{tabular}




\section{Pilot study}

The researcher will randomly distribute the research questionnaires to 35 respondents during the pilot study. The pilot study will be carried in AstraZeneca only. The results of the pilot will be used to enhance the effectiveness of the data collection instrument and to define the procedure to be applied in the actual research. The actual collection of information will commence, only after assessing the results of the pilot study and addressing any issues resulting from it. However, before the actual data collections, the researcher will obtain permission to conduct the actual study in the relevant companies that will be surveyed.

\section{Results}

The research utilized a qualitative survey study approach through questionnaires. Therefore, a survey was conducted involving 5 of the leading pharmaceutical companies, Amgen Inc. Eli Lilly and Company, AstraZeneca, Johnson \& Johnson, and Merck \& Company Inc. The companies were chosen randomly from a sampling frame of 17 pharmaceuticals industry organizations. The researcher used questionnaires, which she mailed to the selected participants in the various companies. The information collected pertained to the principles, assumptions, and processes utilized in designating biologics assets as a Fast to FIH (First-in-Human) program, as well as, to streamline the processes of high and low-risk activities using Fast to First-In-Human (FIH) model and their successful implementation and subsequent readiness for regulatory submission of the clinical trial application (CTA). The questionnaires were directed to members of various departments of the companies involved. Therefore, participants were selected from senior management, quality and control, and research and development departments of the 5 companies. As much quantitative data was collected in terms of numbers and percentages of participants and those who provided information regarding specific themes, the survey was principally qualitative because the information that was required to answer the main research question and test the hypotheses could not be quantified. As indicated by Rahman, 2016, Tolley, Ulin, and Robinson, 2013, researchers should ensure that they collect qualitative information to test hypotheses and answer research questions that are qualitative in nature.

\section{Actual number of interviewed participants}

The researcher had planned an empirical research, whereby a total of 75 members were to be interviewed. This meant that researcher would interview 15 informants from each of the 5 companies. The targeted respondents were employees and senior management staff members from the 5 companies' research and development, quality and control, and senior management departments. The five pharmaceutical companies had been selected randomly from a pool of 17 companies. The researcher had planned to purposively interview 15 employees from each of the 5 selected companies. Therefore, a total of 75 employees were to be interviewed during the survey. The researcher would interview 3 employees from each company's senior management team, 6 employees from the quality control unit of each of the 5 companies, and 6 employees from the research and development department of each of the five companies. Therefore, a total of 15 senior management personnel, 30 quality and control unit employees, and 30 research and development employees were to be interviewed. The intended interview schedule is summarized by the table.

However, the response rate was not $100 \%$ due to some factors that were beyond the control of the researcher. Therefore, instead of obtaining filled questionnaires from three senior staff members from each of the five organizations, the researcher received two answered questionnaires from some organization in some cases. Similarly, the researcher received less than six filled questionnaires from some of the five organizations' quality and control and research and development departments. This means that the researcher received fewer questionnaires than those that had been mailed to the selected participants. In total, 61 out of the possible 75 questionnaires had been filled and returned. The researcher did not make a follow-up on the unreturned questionnaires because the overall response rate was $83 \%$, which was good enough and the researcher went ahead with data analysis. The number of filled and returned questionnaires is summarized in the table below. 
Table 2. Actual interview schedule

\begin{tabular}{|l|l|l|l|l|}
\hline Company Name & \multicolumn{2}{|l|}{ Department } & \\
\cline { 2 - 5 } & Senior Management & $\begin{array}{l}\text { Quality and } \\
\text { Control Unit }\end{array}$ & $\begin{array}{l}\text { Research and } \\
\text { Development }\end{array}$ & \\
\hline Amgen Inc & 2 & 4 & 5 & $\mathbf{1 1}$ \\
\hline $\begin{array}{l}\text { Eli Lilly\& } \\
\text { Company }\end{array}$ & 3 & 5 & 5 & $\mathbf{1 3}$ \\
\hline AstraZeneca & 2 & 5 & 4 & $\mathbf{1 1}$ \\
\hline Johnson \& Johnson & 2 & 6 & 5 & $\mathbf{1 3}$ \\
\hline $\begin{array}{l}\text { Merck \& Company } \\
\text { Inc. }\end{array}$ & 3 & 4 & 6 & $\mathbf{1 3}$ \\
\hline TOTAL & $\mathbf{1 2}$ & $\mathbf{2 4}$ & $\mathbf{2 5}$ & $\mathbf{6 1}$ \\
\hline
\end{tabular}

\section{General quantitative results}

A majority of the participants were male as the questionnaires were completed and returned by 45 male employees while 16 female workers filled the questionnaires and returned them to the researcher. The gender ratio of male to female was approximately $3: 1$. It was expected that the study would attract a 1:1 ratio such that there could be a 50/50 split of females and males. However, this was not achieved because the gender distribution of employees in the involved companies in uneven. Therefore, it was impossible to eliminate researcher bias in terms of gender. The researcher went ahead with analysis of the data collected because the information required to answer the main research question and test the hypotheses could be influenced by gender imbalance. Moreover, the gender make up in the organizations from which the respondents were selected could not be altered. It is imperative to note that the researcher had selected the participants purposively on the basis of the information that they were set to possess. Therefore, gender could not influence the reliability and validity of the data collected because what was required could only be obtained from any employee, whether male or female, who had information and was willing to participate in the study. The gender split ratio may have also been affected by the fact that some participants from the senior management, quality and control, and research and development departments did not take part as projected. Therefore, the number of female respondents was $26 \%$ of the total number of informants while males amounted to $74 \%$ and this equates to 16 questionnaires being filled and returned by women while 45 came from men.

In terms of age, the participants comprised of younger employees, between 24 and 35 years while the elderly, more than 35 years old, were fewer. There were 39 younger employees and 22 older employees who participated in the survey. As can be seen from the above-mentioned statistics, $64 \%$ of the respondents were aged between 24 and 35 years while $36 \%$ of the respondents were older than 35 years, but younger than 51 years. The researcher was satisfied with the age composition of the participants because they possessed the right information that was required for accurate analysis and formulation of valid and reliable inferences. Moreover, the composition of older respondents was significant enough to be relied on as reliable information could be obtained from such employees. On the other hand, the younger participants' was not set to cause any alarm on the accuracy, validity, and reliability of the information gathered from them because they were well-versed with their respective organization's activities.

\section{Qualitative results from content analysis}

Given that the information collected was already in written form, meanings and interpretations were made to come up with categories and sub-categories. Collected data were analyzed using the conventional qualitative content analysis method to come up with findings. In this case, data were coded into categories on the basis of the information available from textual data. The researcher categorized the data and coded it by grouping the information presented through questionnaires into specific categories. To establish directly and quantifiable aspects of the research finding's text content, data were categorized into the themes of "newer principles, assumptions, and processes for designating biologics assets as a Fast to FIH" and "utilization of low and high-risk activities, 
timelines, and functional level expectations." The next step entailed the determination of the quantifiable aspects of text content to find out the relative frequencies of text that fell into each category. The researcher analyzed data through content analysis because it is an unobtrusive approach, given that the research was required only to use the text provided as it was from the source, without interfering with the research content or affecting the outcome. In addition, the approach is inexpensive and can be used in analyzing current events that pose present-day interest. It is manageable while the data it yields can be quantified too. However, the approach was limited to the analysis of recorded information. Therefore, the researcher ensured that she collected recorded information to analyze, which was in the form of written answers to the questions that were presented in a questionnaire. The issue of having recorded information was solved by the use of questionnaires to collect data.

Table 3. Main questions

\begin{tabular}{|c|c|c|}
\hline Category & Questions & $\begin{array}{l}\text { Expected } \\
\text { Response }\end{array}$ \\
\hline $\begin{array}{l}\text { Newer Principles, } \\
\text { Assumptions, and Processes } \\
\text { for Designating Biologics } \\
\text { Assets as a Fast to FIH }\end{array}$ & $\begin{array}{l}\text { 1. Are there newer principles, assumptions, } \\
\text { and processes for designating biologics } \\
\text { assets as a fast to FIH? } \\
\text { 2. Can you confirm that there are newer } \\
\text { principles, assumptions, and processes for } \\
\text { designating biologics assets as a fast to } \\
\text { FIH or not? } \\
\text { 3. Do you feel that the company has not } \\
\text { adopted newer principles, assumptions, } \\
\text { and processes for designating biologics } \\
\text { assets as a fast to FIH? }\end{array}$ & Yes/No \\
\hline $\begin{array}{l}\text { Utilization of Low and High- } \\
\text { Risk Activities, Timelines, } \\
\text { and Functional Level } \\
\text { Expectations }\end{array}$ & $\begin{array}{l}\text { 1. Have the core functional level } \\
\text { expectations in the way the organization } \\
\text { utilizes low and high-risk activities, } \\
\text { timelines, and functional level } \\
\text { expectations changed? } \\
\text { 2. Can you confirm that the core functional } \\
\text { level expectations in the way the } \\
\text { organization utilizes low and high-risk } \\
\text { activities, timelines, and functional level } \\
\text { expectations have changed or not? } \\
\text { 3. Do you feel that core functional level } \\
\text { expectations in the way the organization } \\
\text { utilizes low and high-risk activities, } \\
\text { timelines, and functional level } \\
\text { expectations have not changed? }\end{array}$ & Yes/No \\
\hline
\end{tabular}

Table 4. Categories and sub-categories

\begin{tabular}{|l|c|}
\hline Category & Sub-category \\
\hline Newer Principles, Assumptions, and & - Newer Principles, Assumptions, and \\
Processes for Designating Biologics Assets & Processes for Designating Biologics \\
as a Fast to FIH & Assets as a Fast to FIH \\
& - Not sure whether there are Newer \\
& Principles, Assumptions, and Processes \\
& for Designating Biologics Assets as a \\
& Fast to FIH \\
& - No Newer Principles, Assumptions, and \\
& Processes for Designating Biologics \\
\hline
\end{tabular}




\begin{tabular}{|l|l|}
\hline & Assets as a Fast to FIH \\
\hline Utilization of Low and High-Risk & - Change in the Utilization of Low and \\
Activities, Timelines, and Functional Level & High-Risk Activities, Timelines, and \\
Expectations & Functional Level Expectations \\
& - Not sure whether there the Utilization \\
& of Low and High-Risk Activities, \\
& Timelines, and Functional Level \\
& Expectations has changed \\
& $\begin{array}{l}\text { No Change in the Utilization of Low } \\
\text { and High-Risk Activities, Timelines, } \\
\text { and Functional Level Expectations }\end{array}$ \\
\hline
\end{tabular}

\section{Summary of results}

The findings of the research have established that there have been changes to the procedures, principles, and processes of biologic development, especially those that can be designated as a fast to FIH. The reason for this is that the initial step of developing a biologic is the execution of several tests to find if an element or drug can be used for general therapeutic purposes, after which further tests are carried out to find out whether it can be used for oncology therapeutic purposes. This is unlike the standard processes, principles, and assumptions that discovery of a potential element or drug that can be developed for oncology therapeutic purposes is the first step in the biologic development procedure as indicated by FDA (2017a). It was established that preclinical tests are still executed during the development and designation of a biologic asset as a fast to FIH. Therefore, it should be noted that preclinical tests were necessary while pharmaceutical organizations ensure that the biologic molecule to be designated as a fast to FIH successfully passes the preclinical tests and proves to be effective in oncology and immuno-oncology therapeutics. Therefore, the proposed biologic should meet the safety and efficacy standards set by FDA because each step of the process that is followed in the development of a biologic asset is expensive and risky.

Research findings further affirm that the execution of in-vitro studies, followed by in-vivo studies is still maintained in the development of biologic assets that can be designated as a fast to FIH. In this case, in-vitro studies are performed in a controlled environment, outside of an organism to determine the possible effects that a designated biologic drug may have on an animal or a person. On the other hand, in-vivo studies, on the other hand, are performed on a living organism to find out the real expected effect of a biologic drug on an animal or human being. The pharmaceutical organization still adheres to the principle of executing additional clinical studies (FDA, 2017b).

\section{Findings and discussion}

\section{Findings based on themes}

\section{Discovery of a potential element or drug that can be developed for oncology therapeutic purposes}

From the questionnaire filled and returned, 48 out of the 61 respondents (79\%) indicated that the first step of developing a biologic that can be designated as an asset to be used as a fast to FIH is no longer the discovery of a potential element or drug that can be developed for oncology therapeutic purposes. Instead, they indicated that the first step of the procedure was the execution of several tests to find if an element or drug can be used for general therapeutic purposes, after which further tests are carried out to find out whether it can be used for oncology therapeutic purposes. The number of respondents who indicated that there had to be tested to find out if an element or drug can be used for general therapeutic purposes, rather than specific oncology therapy was significant enough to conclude that there are newer principles, assumptions, and processes for designating a biologic assets as a fast to FIH These findings are contradictory to the assertions of the Institute of Medicine (US) Committee (2010), which indicates that the first step of developing a biologic asset to be designated as an asset that can be used as a fast to FIH is the finding out of a common or rare drug or element that has the potential of being used effectively for oncology. Only 13 of the respondents $(21 \%)$ 
indicated that the process of designating a biologic asset as a fast to FIH remained the same as it started with the discovery of a potential element or drug that can be developed specifically for oncology therapeutic purposes. Therefore, it was concluded that there is a change in the principles, processes, and assumptions that are adopted when designating a biologic asset as a fast to FIH.

\section{Designation of a biologic asset as a fast to fih through the execution of preclinical tests}

A significant percentage of the informants, $81 \%$, indicated that the execution of preclinical tests is still used as a process stage towards the designation of a biologic asset as a fast to FIH. However, it was not the first step in the procedure as the discovery of a drug element comes before it. The respondents further indicated that the preclinical tests were necessary, but they are not the even the first or second step of the process of designating a biologic asset as a fast. The reason for this is that there are two previous stages that a biologic asset set to be designated as a fast to FIH that will have to be performed. The initial steps are the discovery of a drug or element that can be used for therapeutic purposes and the testing of whether that element can be used specifically for oncology therapeutic purposes. This is because biologics are used to treat chronic diseases, especially cancer (Mócsai, Kovács, \& Gergely, 2014). However, the informants confirmed that the preclinical stage still involves thorough test because it is succeeded by other phases that become complex at every successive step. It was indicated that this phase has to enhance testing with successful clinical results to support approval for marketing and adoption of the biologic. The number of informants who indicated that they feel nothing has changed and that the execution of preclinical tests still holds its chronological place in the procedure was quite insignificant at $19 \%$. Therefore, it was established that there had been remarkable changes in the procedures followed when developing a biologic asset that can be designated as a fast to FIH. However, it was noted that that the discovered biologics should have the potential of becoming effective oncology and immuno-oncology therapies. The reason for this is that sometimes the chances of success are very low for some drugs development efforts while the costs of development are very high. Drugs with a low potential are dropped while those with the highest potential are developed because all the biotechnology and pharmaceutical companies emphasize on an excellent financial return. Kingham, Klasa, and Carver (2014), also established that, as it is the case with other drugs, biologics should undergo laboratory and animal testing because this process enhances the determination and definition of the pharmacologic and toxicological effects. It is a vital step that helps in preventing any harm from the biologics because it is carried out before the drugs are studied on humans because FIH tests are done on humans (Eisenhauer, Twelves, \& Buyse, 2015). Therefore, the legal requirements for the development of biologic drugs are similar to those of other drugs. In that case, the FDA's requirement of execution and observation of good laboratory practices and related regulations are applied. However, the researchers indicated that, in the case of biologics, pharmaceutical organizations should adopt a flexible and case-by-case approach to analysis and execution of preclinical testing because they are special.

Table 5. Quantified results

\begin{tabular}{|l|l|l|l|l|}
\hline & \multicolumn{2}{|l|}{$\begin{array}{l}\text { "Newer Principles, Assumptions, } \\
\text { and Processes for Designating } \\
\text { Biologics Assets as a Fast to FIH" }\end{array}$} & \multicolumn{2}{l|}{$\begin{array}{l}\text { "Utilization of Low and High-Risk } \\
\text { Activities, Timelines, and Functional } \\
\text { Level Expectations" }\end{array}$} \\
\hline & Yes & No & Yes & No \\
\hline $\begin{array}{l}\text { Senior Management } \\
\text { Department }\end{array}$ & 9 & 3 & 10 & 2 \\
\hline $\begin{array}{l}\text { Quality and Control } \\
\text { Unit Department }\end{array}$ & 19 & 5 & 23 & 1 \\
\hline $\begin{array}{l}\text { Research and } \\
\text { Development } \\
\text { Department }\end{array}$ & 20 & 5 & 19 & 6 \\
\hline Totals & 48 & 13 & 52 & 9 \\
\hline
\end{tabular}


Table 5. Quantified results in percentage form

\begin{tabular}{|c|c|c|c|c|c|c|c|c|}
\hline & & \multicolumn{2}{|c|}{$\begin{array}{l}\text { "Newer } \\
\text { Principles, } \\
\text { Assumptions, and } \\
\text { Processes for } \\
\text { Designating } \\
\text { Biologics Assets } \\
\text { as a Fast to FIH" }\end{array}$} & & & \multicolumn{2}{|c|}{$\begin{array}{l}\text { "Utilization of Low } \\
\text { and High-Risk } \\
\text { Activities, } \\
\text { Timelines, and } \\
\text { Functional Level } \\
\text { Expectations" }\end{array}$} & \\
\hline & Yes & $\%$ & No & $\%$ & Yes & $\%$ & No & $\%$ \\
\hline $\begin{array}{l}\text { Senior } \\
\text { Management } \\
\text { Department }\end{array}$ & 9 & 75 & 3 & 25 & 10 & 83 & 2 & 17 \\
\hline $\begin{array}{l}\text { Quality and } \\
\text { Control Unit } \\
\text { Department }\end{array}$ & 19 & 79 & 5 & 21 & 23 & 96 & 1 & 4 \\
\hline $\begin{array}{l}\text { Research and } \\
\text { Development } \\
\text { Department }\end{array}$ & 20 & 80 & 5 & 20 & 19 & 76 & 6 & 24 \\
\hline Totals & 48 & 79 & 13 & 21 & 52 & 85 & 9 & 15 \\
\hline
\end{tabular}

According to the informants who said that their organizations had assumed newer assumptions, principles, and processes of designating biologics assets as a fast to FIH, explained that the approach to deciding the molecular element that should be used as a biologic has slightly changed. For instance, initially, the prerequisite for the development of a biologic involved the discovery of a potential element or drug that could be developed for therapeutic purposes. However, currently, biologics assets developers use a trial and error method, whereby they decide to find out whether an element, which they expect to be a potential fast to FIH and then go ahead to determine its potential and performance through scientific tests. It is after several tests that the researchers are able to determine whether the discovered biologic or drug can be used effectively for oncology. Given that the proposed biologic is not predetermined before it is chosen, it may be common or rare, but it is a requirement that due processes are followed in designing the biologic asset, irrespective of its scarcity or abundance status. The common principles that guide the development and manufacturing process of a biologic asset that can be designated as a fast to FIH usually focus on ensuring that the approaches used are capable of producing drug substances of the intended quality in a consistent manner (FDA, 2012). The first principle requires that a biologic should possess drug qualities that are known and intended. For instance, the proposed biologic's physical, chemical, biological, and microbiological characteristics should be known. The reason for this is that they usually influence the development process of the product. For instance, the solubility of a drug substance can have an impact on the possible uses and dosage of the drug to be developed.

\section{Conclusions}

The findings of the research have established that there have been changes to the procedures, principles, and processes of biologic development, especially those that can be designated as a fast to FIH. The reason for this is that the initial step of developing a biologic is the execution of several tests to find if an element or drug can be used for general therapeutic purposes, after which further tests are carried out to find out whether it can be used for oncology therapeutic purposes. This is unlike the standard processes, principles, and assumptions that discovery of a potential element or drug that can be developed for oncology therapeutic purposes is the first step in the biologic development procedure as indicated by FDA (2017a). It was established that preclinical tests are still executed during the development and designation of a biologic asset as a fast to FIH. Therefore, it should be noted that preclinical tests were necessary while pharmaceutical organizations ensure that the biologic molecule to be designated as a fast to FIH successfully passes the preclinical tests and proves to be effective in oncology and immuno-oncology therapeutics. Therefore, the proposed biologic should meet the safety 
DOI: $10.21522 / \mathrm{TIJCR} .2014 .05 .01 . A r t 008$

ISSN: $2520-3096$

and efficacy standards set by FDA because each step of the process that is followed in the development of a biologic asset is expensive and risky.

\section{References}

[1]. Adler, E. S., \& Clark, R. (2014). An invitation to social research. Belmont, CA: Cengage Learning.

[2]. Andrew X. Zhu, P. J.-k., \& Philip, P. A. (2013). First-in-Man Phase I Study of GC33, A Novel Recombinant Humanized Antibody against Glypican-3, in Patients with Advanced Hepatocellular Carcinoma. Clinical Cancer Research.

[3]. Atanasov, A. G., et al. (2015). Discovery and resupply of pharmacologically active plant-derived natural products: A review. Biotechnology Advances, 33(8), 1582-1614.

[4]. Bartlett, D. L. (2011). Surgical Oncology: Fundamentals, evidence-based approaches and new technology. New Delhi: Jaypee Brothers Pvt. Ltd.

[5]. Berger, A. A. (2011). Media and communication research methods: An introduction to qualitative and quantitative approaches. Thousand Oaks: SAGE Publications.

[6]. Bumbaca, D., et al. (2011). Highly specific off-target binding identified and eliminated during the humanization of an antibody against FGF receptor 4. MAbs Journal, 3(4), 376-386.

[7]. Conner, J., et al. (2014). Biotechnology entrepreneurship. New York: Elsevier Inc.

[8]. Creswell, J. W. (2014). Research design: Qualitative, quantitative, and mixed methods approaches. Thousand Oaks, CA: SAGE Publications.

[9]. Dostalek, M., Prueksaritanont, T., \& Kelley, R. (2017). Pharmacokinetic de-risking tools for selection of monoclonal antibody lead candidates. MAbs Journal, 9(5), 756-766.

[10]. Ehnert, I. (2009). Sustainable human resource management: A conceptual and exploratory analysis from a paradox perspective. Heidelberg: Physica-Verlag Press.

[11]. Eisenhauer, E. A., Twelves, C., \& Buyse, M. E. (2015). Phase I Cancer Clinical Trials : A Practical Guide. New York: Oxford University Press.

[12]. European Medicines Agency. (1988). Pharmacokinetic Studies in Man. Retrieved 09 15, 2017, from European Medicines Agency: Retrieved from

http://www.ema.europa.eu/ema/index.jsp?curl=pages/regulation/general/general_content_001289.jsp\&mid=WC 0b01ac0580032ec5

[13]. FDA. (2017a). Step 2: Preclinical research. Retrieved from

https://www.fda.gov/forpatients/approvals/drugs/ucm405658.htm

[14]. FDA. (2017b). Step 3: Clinical research. Retrieved from https://www.fda.gov/forpatients/approvals/drugs/ucm405622.htm

[15]. FDA. (2017c). Inside clinical trials: Testing medical products in people. Retrieved from https://www.fda.gov/drugs/resourcesforyou/consumers/ucm143531.htm

[16]. Feldman, E. J., Lancet, J. E., Kolitz, J. E., Ritchie, E. K., Roboz, G. J., \& List, A. F. (2011). First-In-Man Study of CPX-351. Journaal of Clinical Oncology, 979-985.

[17]. Food and Drug Agency. (2005). Guidance for Industry:Clinical Studies. New York: Rockville,.

[18]. Forum on Neuroscience and Nervous System Disorders,Board on Health Sciences Policy, \& Institute of Medicine. (2014). Improving and accelerating therapeutic development for nervous system disorders: Workshop summary. Washington DC: National Academies Press.

[19]. Gad, S. C. (2011). Safety evaluation of Pharmaceuticals and Medical Devices : International Rregulatory Guidelines. New York: Springer.

[20]. Giese, G. (2017). Clinical pharmacology 1: Phase 1 studies and early drug. Retrieved from https://www.fda.gov/downloads/training/clinicalinvestigatortrainingcourse/ucm340007.pdf.

[21]. Hanauer, S. B. (2008). The ethics of phase I trials of biologic agents. Nature Clinical Practice Gastroenterology \& Hepatology, 5(10), 533.

[22]. History of Vaccines. (2017). Vaccine development, testing, and regulation. Retrieved from https://www.historyofvaccines.org/content/articles/vaccine-development-testing-and-regulation

[23]. Hojjat-Farsangi, M. (2014). Small-Molecule Inhibitors of the Receptor Tyrosine Kinases: Promising tools for targeted cancer therapies. International Journal of Molecular Sciences, 15(8), 13768-13801.

[24]. Institute of Medicine (US) Committee. (2010). Accelerating Rare Diseases Research and Orphan Product Development. In M. J. Field, \& T. Boat, Rare Diseases and Orphan Products: Accelerating Research and 
Development (p. Chapter 5: Development of New Therapeutic Drugs and Biologics for Rare Diseases). Washington DC: National Academies Press. Available from: https://www.ncbi.nlm.nih.gov/books/NBK56179/. [25]. Klein, J., \& Blaser, G. (2016, Novemeber). Expression of next generation biologics requires next generation expression systems. Retrieved from

http://bio.lonza.com/uploads/tx_mwaxmarketingmaterial/Lonza_Webinars_Next_Generation_Expression_Syste ms.pdf

[26]. Kudrin, A. (2012). Overview of cancer vaccines. Human Vaccines Immunother, 8(9), 1335-1353. doi: $10.4161 /$ hv.20518.

[27]. Li, F., et al. (2010). Cell culture processes for monoclonal antibody production. MAbs Journals, 2(5), 466477.

[28]. Li, Y., et al. (2016). Quantitation and pharmacokinetic modeling of therapeutic antibody quality attributes in human studies. MAbs Journal, 8(6), 1079-1087.

[29]. Lybecker, K. M. (2016, January). The biologics revolution in the production of drugs. Retrieved from https://www.fraserinstitute.org/sites/default/files/biologics-revolution-in-the-production-of-drugs.pdf.

[30]. Macnee, C. L., \& McCabe, S. (2008). Understanding nursing research: Using research in evidence-based practice. Philadelphia, PA: Wolters Kluwer Health/Lippincott Williams \& Wilkins.

[31]. Marion, D. (2013). An Introduction to Biological NMR Spectroscopy. Mol Cell Proteomics , 12(11), 30063025.

[32]. Medina, C. (2003). Compliance handbook for pharmaceuticals, medical devices, and biologics. London: CRC Press.

[33]. Mócsai, A., Kovács, L., \& Gergely, P. (2014). What is the future of targeted therapy in rheumatology: biologics or small molecules? BMC Medicine, 12(43), 1-9.

[34]. Phrma. (2017). Biopharmaceutical research \& development: The process behind new medicines. Retrieved from http://phrma-docs.phrma.org/sites/default/files/pdf/rd_brochure_022307.pdf.

[35]. Prueksaritanont, T., \& Tang, C. (2012). ADME of biologics—What have we learned from small molecules? The AAPS Journal , 14(3), 410-419.

[36]. Rahman, M. S. (2016). The advantages and disadvantages of using qualitative and quantitative Approaches and methods in language "testing and assessment" research: A literature review. Journal of Education and Learning, 6(1), 102-112.

[37]. Roberts, A. (2015). Maintaining the stability of biologics. BioPharm International Journal, 28(3), 38-41.

[38]. Rosenberg, A., \& Demeule, B. (2015). Biobetters: Protein engineering to approach the curative. New York: Springer Publications.

[39]. Rubin, A., \& Babbie, E. R. (2010). Essential research methods for social work. Belmont, CA: Brooks/Cole, Cengage Learning Press.

[40]. Suh, H. Y., Peck, C. C., Yu, K.-S., \& Lee, H. (2016). Determination of the starting dose in the first-inhuman clinical trials with monoclonal antibodies: a systematic review of papers published between 1990 and 2013. Drug Design, Development and Therapy.

[41]. The Conversation. (2015, August 5). Explainer: what are biologics and biosimilars? Retrieved from https://theconversation.com/explainer-what-are-biologics-and-biosimilars-45308.

[42]. Tibbitts, J., et al. (2016). Key factors influencing ADME properties of therapeutic proteins: A need for ADME characterization in drug discovery and development. MAbs Journal, 8(2), 229-245.

[43]. Tolley, E. E., Ulin, P. R., \& Robinson, E. T. (2013). Qualitative methods in public health: A field guide for applied research. San Francisco, CA: Jossey-Bass Press.

[44]. U.S. Department of Health and Human Services, et al. (2015, July). Analytical procedures and methods validation for drugs and biologics: Guidance for industry. Retrieved from https://www.fda.gov/downloads/drugs/guidances/ucm386366.pdf.

[45]. Vugmeyster, Y., et al. (2011). Complex pharmacokinetics of a humanized antibody against human amyloid beta peptide, anti-abeta Ab2, in nonclinical species. Pharmaceutical Research, 28(17), 1696-1706.

[46]. Waltz, E. (2014). It's official: Biologics are pharma's darlings. Nature Biotechnology, 32(2), 117.

[47]. Wang, W., \& Prueksaritanont, T. (2010). Prediction of human clearance of therapeutic proteins: Simple allometric scaling method revisited. Biopharmaceutics \& Drug Disposition Journal , 31, 253-263.

[48]. Wang, W., \& Singh, M. (2014). Biological drug products: Development and strategies. New York: John Wiley \& Sons, Inc. 
DOI: $10.21522 /$ TIJCR.2014.05.01.Art008

ISSN: 2520-3096

[49]. Wang, W., et al. (2011). Monoclonal antibodies with identical Fc sequences can bind to FcRn differentially with pharmacokinetic consequences. Drug Metabolism and Disposition Journal, 39, 1469-1477.

[50].Wiley, F. (2016, July). What are biologics? Retrieved from https://medshadow.org/features/what-arebiologics/.

[51]. Wong, G. (2009). Biotech scientists bank on big pharma's biologics push. Retrieved from https://www.nature.com/nbt/journal/v27/n3/full/nbt0309-293.html.

[52]. Zhao, L., Ren, T.-h., \& Wang, D. D. (2012). Clinical Pharmacology Considerations in Biologics Development. Acta Pharmacologica Sinica, 1339-1347.

[53]. Zimney, E. (2008). Understanding biologics: How they differ from Drugs and why they cost more. Retrieved 09 15, 2017, from Every Day health: http://www.everydayhealth.com/columns/zimney-health-andmedical-news-you-can-use/understanding-biologics-how-they-differ-from-drugs-and-why-they-cost-more/. 